\title{
Fórmula estratégica empresarial para pymes en Ecuador ante la covID-19
}

\author{
María Cristina Useche Aguirre* \\ Lourdes Maribel Vásquez Lacres ${ }^{\star *}$ \\ Flor Isabel Salazar Vázquez ${ }^{\star \star *}$ \\ Magdalena Ordóñez Gavilanes ${ }^{\star \star \star *}$
}

Fecha de recibido: 3 de julio de 2020

Fecha de aprobado: 19 de octubre de 2020

Para citar este artículo: Useche Aguirre, M. C., Vásquez Lacres, L. M., Salazar Vázquez, F. I., \& Ordóñez Gavilanes, M. (2021). Fórmula estratégica empresarial para pymes en Ecuador ante la covid-19. Revista Universidad \& Empresa, 23(40), 1-22. https://doi.org/10.12804/revistas.urosario.edu.co/empresa/a.9309

\section{Resumen}

Ante las desgarradoras consecuencias generadas por la pandemia la covid-19, el Gobierno del Ecuador tomó medidas económicas y sociales para prevenir contagios masivos; sin embargo, las pymes decidieron mantenerse en funcionamiento, pues el sustento diario familiar depende totalmente de sus esfuerzos económicos, y ante sucumbir en estos tiempos han preferido arriesgarse e ir solucionando sus necesidades

* Economista. Magíster en Gerencia de Empresas (mención en Mercadeo). Doctora en Ciencias Económicas. Docente e investigadora del Centro de Estudios de Empresa de la Facultad de Ciencias Económicas y Sociales de la Universidad del Zulia (Venezuela). Correo electrónico: mariauseche@yahoo.es ORCID: https://orcid.org/0000-001-5057-0034

** Ingeniera empresarial. Magíster en Gestión Empresarial. Docente y directora de la Carrera de Administración de Empresas de la Universidad Católica de Cuenca (Ecuador). Correo electrónico: ivasquezl@ucacue.edu.ec ORCID: https://orcid.org/00000003-3984-8800.

*** Ingeniera empresarial. Máster en Auditoría Integral. Máster en Docencia Superior. Docente de la Universidad Católica de Cuenca (Ecuador). Correo electrónico: fisalazarv@ucacue.edu.ec ORCID: https://orcid.org/0000-0002-0071-0139

**** Ingeniera empresarial. Magíster en Gestión Empresarial. Doctora (c) en Ciencias Sociales (mención en Gerencia). Docenteinvestigadora de la Universidad Católica de Cuenca, extensión Cañar (Ecuador). Correo electrónico: mordonez@ucacue. edu.ve ORCID: https://orcid.org/0000-0001-7864-1314. 
básicas en la medida de sus posibilidades, aunque ello implique un posible contagio. Ante esto, el objetivo fue establecer las estrategias empresariales implementadas por las pymes en la República del Ecuador en el marco de la pandemia. En tal sentido, se ha empleado un tipo de investigación documental, acudiendo a fuentes institucionales, gubernamentales y empresariales de ese país, y la información extraída ha pasado por un proceso de depuración y análisis con la técnica del análisis de contenido. Se concluye que las pymes requieren atender sus necesidades sociales y los requerimientos económicos que impone el mercado nacional e internacional y para ello se diseñaron cuatro estrategias interactivas para preservar la salud y adecuar sus acciones a la tecnología, estimular la capacidad de rápida adaptación ante adversidades e insertar su direccionamiento con los objetivos de desarrollo sostenible.

Palabras clave: estrategias empresariales; pequeñas y medianas empresas; crisis

socioeconómica; pandemia por covid-19; Ecuador.

\title{
Business Strategic Formula for SMES in Ecuador to face COVID-19
}

\begin{abstract}
Given the heartbreaking consequences generated by the covid-19 pandemic, the government of Ecuador took economic and social measures to prevent massive infections. However, small and medium-sized companies decided to keep operating. Since most families depend entirely on their economic efforts and before succumbing, they prefer to take risks and solve their immediate basic needs to the best of their ability, even if it implies possible contagion. Given this, the objective of this work is to establish the business strategies implemented by small and medium-sized companies in the Republic of Ecuador in the framework of the covid-19 pandemic. In this sense, a type of documentary research has been used, going to institutional, governmental, and business sources in that country. The information extracted was filtered and analyzed with the content analysis technique. It is concluded that smes need to meet their social needs and the economic requirements imposed by the national and international markets. For this, three interactive strategies were designed: to preserve health and adapt their actions to technology, to stimulate the ability to adapt to adversities, and to insert employer's directions with sustainable development goals.
\end{abstract}

Keywords: Business strategies; small and medium-sized companies; socioeconomic crisis; Covid-19 pandemic; Ecuador.

\section{Fórmula estratégica empresarial para PMES no Equador durante o covid-19}

\section{Resumo}

Diante das desastrosas consequências geradas pela pandemia covid-19, o governo do Equador tomou medidas econômicas e sociais para prevenir contágios massivos, o entanto, pequenas e médias empresas decidiram seguir em funcionamento, pois o sustento familiar diário depende totalmente de seus esforços econômicos e estando sujeitos a sucumbir nestes tempos, preferem se arriscar e ir solucionando suas necessidades básicas conforme suas possibilidades, ainda que isso implique em possível contágio. Diante disso, o objetivo do presente trabalho pretende estabelecer as estratégias empresariais empregadas por pequenas e médias empresas na República do Equador diante da pandemia covid-19. Nesse sentido, empregou-se um tipo de investigação documental, recorrendo a fontes institucionais, governamentais e empresariais desse país, e a informação extraída passou por um processo de depuração e análise utilizando a técnica de análise de conteúdo. Conclui-se que as pmes precisam atender suas necessidades sociais e os requerimentos econômicos impostos pelos mercados nacional e internacional, e, para isso, desenharam-se quatro estratégias interativas para preservar a saúde e adequar suas ações perante a tecnologia, estimular a capacidade de rápida adaptação frente às adversidades e inserir seu direcionamento aliado aos objetivos de desenvolvimento sustentável.

Palavras-chave: estratégias de negócios; pequenas e médias empresas; crise socioeconômica; pandemia de covid-19; Equador. 


\section{Introducción}

En América Latina, el aislamiento social o confinamiento perturbó el dinamismo empresarial y afectó de manera negativa los ingresos de las empresas, e independientemente de su tamaño, enfrentan importantes dificultades para el acceso al crédito y aumento de la probabilidad de insolvencias financieras. Entre las actividades económicas más afectadas se encuentran el comercio al por mayor y al por menor, reparación de bienes, hoteles, restaurantes, transporte, almacenamiento, comunicaciones, turismo y servicios en general, respectivamente, pero en definitiva las pequeñas y medianas empresas (pymes) han sentido el mayor impacto, porque su "elevada participación [...] en la creación del empleo (más del 50\% del empleo formal) aumenta los impactos negativos, pues este sector ha sido duramente afectado por la crisis" (Comisión Económica para América Latina y el Caribe, 2020, p. 16). Dimensionar la caída de la actividad económica permite determinar la magnitud del esfuerzo para un regreso a la normalidad; pero ese regreso no será una vuelta a la situación existente antes de la pandemia, pues ha habido cambios en el mercado que exigen modificaciones estructurales en las actividades productivas que están en funcionamiento para minimizar impactos irreversibles, en las condiciones laborales, el empleo, el bienestar social, entre otros.

Ante estimaciones de las consecuencias de la pandemia, el Fondo Monetario Internacional (2020) está recibiendo un número sin precedentes de solicitudes de asistencia, de más de noventa países, entre ellos Ecuador, Honduras, Madagascar, Ruanda o Togo. En el caso de Ecuador, su solicitud obedece a que es el segundo país de América Latina que más vidas perdió en la región en el primer trimestre del 2020, generando caos en todo el sistema nacional, por lo que se categoriza como una crisis sanitaria sin precedentes para el país, de acuerdo con Juan Carlos Zevallos (2020), ministro de Salud de Ecuador.

En ese marco latinoamericano, según la Comisión Económica para América Latina y el Caribe (2020, p. 12), las proyecciones de crecimiento del producto interno bruto para Ecuador tienen estimaciones negativas (-6.5\%), lo cual generará efectos perjudiciales en todas las actividades económicas, especialmente en el sector comercio y servicios, que son los que sostienen principalmente la economía de ese país, lo que a su vez incidirá de la misma manera 
en las pymes (las cuales representan el 99.54\% de las organizaciones de la nación, con estructuras micro, pequeñas y medianas) (Instituto Nacional de Estadística y Censos [INEC], 2017).

Indiscutiblemente, la realidad ecuatoriana en el marco del sistema capitalista se encuentra en desequilibrio e inserta en una crisis sistémica dinámica y con mucha incertidumbre, que arropa también el ámbito empresarial en Ecuador y, por ende, a las pymes, por lo que la realidad empresarial está influenciada por la interacción de múltiples fuerzas de tipo económico, político, sociocultural, tecnológico, ambiental, entre otras, que lo afectan de forma directa e inciden en su campo de acción. Ello genera impactos no favorables, como reducción de la demanda (nacional e internacional) y de sus ingresos, dificultades para acceder a insumos, reducción o falta de mano de obra, difícil acceso a financiamiento y procesos productivos, que no están ajustados a las urgencias coyunturales para ser operados de manera remota o automatizada.

Estas dificultades exigen a las pymes en Ecuador emplear sus bondades, como la agilidad y flexibilidad ante este entorno sistémico, complejo e incierto; pero sobre todo se ha hecho evidente la necesidad de actuar reactivamente, para afrontar los retos impuestos por la pandemia, así como sus implicaciones sanitarias, sociales y económicas. De ahí que el objetivo de este artículo sea establecer las estratégicas empresariales de las pymes en la República del Ecuador en el marco de la pandemia ${ }^{1}$ por covid-19.

\section{Metodología}

Este trabajo se desarrolló desde la investigación documental, mediante un proceso sistemático de indagación, recolección, organización e interpretación de información sobre resultados de investigación, reflexiones teóricas y publicaciones institucionales, gubernamentales y empresariales en América Latina y Ecuador, a fin de reflexionar sobre las circunstancias que enfrentar el entorno ante la atmósfera de la Covid-19 para la elaboración de estrategias (Alfonzo, 1994). En esta revisión documental se implementó la técnica

\footnotetext{
"En términos per cápita es el primero en Sudamérica y el segundo en toda América Latina, por detrás de Panamá. Según datos del Coronavirus Resource Center de la Johns Hopkins University, a 2 de abril Panamá tenía 0.76 muertos por coviD-19 por cada 100.000 habitantes (32 muertos hasta ahora), y Ecuador 0.57 (98 muertos)" (Milla, 2020, p. 1).
} 
de análisis de contenido que, de acuerdo con Mayring es "una aproximación empírica, de análisis metodológicamente controlado de textos al interior de sus contextos de comunicación, siguiendo reglas analíticas de contenido y modelos paso a paso, sin cuantificación de por medio" (2000, p. 4). El empleo de esta técnica facilita la descripción sistemática del contenido y ello permite combinar datos tanto cuantitativos como cualitativos y exponer con mayor completitud el tema que se aborda.

\section{Panorama ecuatoriano de las pymes ante la pandemia por Covid-19}

Las pymes ocupan un lugar muy importante dentro de la economía latinoamericana, "siendo un componente fundamental del tejido empresarial en América Latina. Esta importancia se manifiesta en varias dimensiones, su participación en el número total de empresas o la creación de empleo" (Correa et al., 2019, p. 9). En el Ecuador, las pymes ${ }^{2}$ se erigen como dinamizadoras de la economía pues, de acuerdo con el INEC (2017), en ese país el 99\% de los negocios se desempeñan bajo esta modalidad empresarial, por lo que, según Yance Carvajal et al. (2017) son "la fuente del desarrollo social en cuanto a producción, demanda y compra de productos o simplemente por valor agregado, lo que significa que se ha convertido en un factor indispensable para generar riqueza y empleo" (p. 10).

Sin embargo, las pymes deben enfrentar una crisis tanto social como económica. La primera requirió que el Gobierno nacional emitiese el Decreto Presidencial 1017 (Moreno, 2020), en el cual se declaró un estado de excepción ante la emergencia sanitaria en el país por las incidencias de la covid-19 en la población, lo que determinó la suspensión de todas las actividades económicas, ${ }^{3}$ y la segunda refleja escenarios poco promisorios, pues de acuerdo con el Banco Central de Ecuador (2020), la economía nacional "para el año 2020 presenta un decrecimiento interanual que se encuentra en un rango comprendido entre $-7.3 \%$ y $-9.6 \% "$ (p. 1).

2 Las pequeñas y medianas empresas en Ecuador se desempeñan siguiendo las orientaciones de Ley Orgánica de la Economía Popular y Solidaria y del Sector Financiero Popular y Solidario (Asamblea Nacional de la República del Ecuador, 2011).

3 A excepción de los sectores de salud, seguridad alimentaria, sector financiero, transporte de personal sanitario y sectores estratégicos. 
Aunadamente a ese decrecimiento, explica el Banco Central de Ecuador (2020) que en el primer trimestre hubo una caída de 28.3 dólares por barril en los precios del petróleo (principal producto de exportación) y, por lo tanto, una reducción en el dinamismo en la demanda externa de productos no petroleros, ante la desaceleración económica mundial por la pandemia, lo cual conducirá a una disminución de la formación bruta de capital fijo (inversión) de $\mathbf{1 4 . 0} \%$ en este año con respecto al anterior. La balanza comercial también tiene repercusiones negativas, pues igualmente habrá una caída de las importaciones de bienes de capital por 1818 millones de dólares; así mismo, las exportaciones también tendrán cifras negativas del 5.2\% en 2020, producto de la contracción en las exportaciones no petroleras y petroleras que experimentarán una caída esperada del 4\%. Esta información ha conllevado al Gobierno ecuatoriano a una:

[...] disminución del gasto público en $5.6 \%$ en el año 2020, en los rubros de sueldos y salarios, y en la compra de bienes y servicios. Con fecha 19 de mayo, se dispuso una reducción de dos horas de la jornada laboral para las instituciones públicas del sector ejecutivo, lo que implica una disminución del $16.66 \%$ del salario y para el sector de Educación de 8.33 \% (reducción de una hora diaria), con la excepción de los servidores de la salud y de la fuerza pública. La reducción de salarios se realizará por un período de seis meses, renovables por otros seis meses. (Banco Central de Ecuador, 2020, p. 1)

Ante este panorama, coadyuvar a la recuperación económica de la nación por parte de las pymes impone superar debilidades históricas, procurar insertarse en mercados dinámicos, participar formalmente en relaciones productivas más dinámicas con grandes empresas e integrarse en modelos asociativos con otras empresas, a fin de generar economías de escala y bienes colectivos. Para que ello sea posible, se requiere una gerencia dinámica, capaz de administrar ante la complejidad actual del Ecuador, afrontar la incertidumbre, al igual que utilizar la flexibilidad, la concertación y hasta la imaginación, a efectos de anticiparse a los cambios y salir de la crisis y de inadecuadas estructuras productivas.

La vulnerabilidad de la salud pública, la fase recesiva de la economía y la falta de orientación estratégica de las pymes en la activación productiva son desafíos que deben afrontar las pymes, aprovechando sus ventajas (tamaño y flexibilidad), que les permiten adaptarse oportunamente a las necesidades y circunstancias del mercado y, por lo tanto, generar respuestas rápidas a los cambios del entorno e integrarse como eslabón en las cadenas de 
producción con proveedores de bienes intermedios o finales y de servicios, que alimentan el surgimiento de empresas nacionales más grandes.

Para paliar la situación socioeconómica y ayudar a las pymes, la Asamblea Nacional de la República del Ecuador (2020) aprobó la Ley de Apoyo Humanitario que promueve acuerdos laborales, pensiones educativas, tarifas para servicios básicos, facilidades financieras, convenios entre deudores y acreedores, entre otros, para combatir la crisis sanitaria derivada de la covid-19, apoyar la sostenibilidad del empleo y facilitar acuerdos entre empleador y empleado. Por ejemplo, en el ámbito laboral se indicaron directrices para la implementación del teletrabajo, así como la reducción, modificación o suspensión de la jornada laboral durante la emergencia sanitaria, que permite a los empleadores acordar diferentes modalidades de trabajo. Si bien es cierto que todos esos aspectos son importantes para ofrecer estabilidad social, también vale la pena destacar en sus consideraciones transitorias el apoyo a la creación de nuevos emprendimientos. Al respecto señala que:

\footnotetext{
El Estado garantizará la apertura de nuevos emprendimientos desde el día cero, sin ningún tipo de requisitos. Para efectuar este puntual, los gobiernos autónomos descentralizados, así como cualquier entidad pública, emitirán permisos de operación provisional que tendrán una validez de 180 días. En este tiempo, los emprendedores deberán regularizar su actividad en temas tributarios, municipales y permisos de toda índole. (Asamblea Nacional de la República del Ecuador, 2020, p. 16)
}

Con el objeto de mantener la liquidez del sector productivo, se acordó una política financiera que vela por el "diferimiento de plazos en créditos que mantienen las pymes, tanto con la banca pública como con la privada, así como diferimiento del pago de planillas de servicios básicos de abril y mayo y refinanciamiento de préstamos hipotecarios y quirografarios" (Ministerio de Relaciones Exteriores y Movilidad Humana, s. f., p. 2). Paralelamente, se creó un plan de reactivación productiva que integra acciones del sector público, del privado y la cooperación internacional, impulsando el marketing digital para publicitar el comercio y el uso de tecnología en la activación del comercio electrónico.

Como se puede observar, todas estas acciones impulsadas por el Gobierno nacional son pertinentes a la coyuntura; sin embargo, son insuficientes para la reactivación económica, dado que se requieren esfuerzos contundentes gerenciales por parte de las pymes para 
afrontar un mercado diferente, con condiciones y necesidades distintas a las que venían manejando meses atrás, pues las prioridades de consumo han cambiado, así como el poder adquisitivo de los consumidores. Ello implica repensar sus negocios y reconsiderar sus prioridades de inversión; de ahí que el próximo apartado sea de interés en este trabajo, pues se presentan un conjunto de orientaciones estratégicas empresariales acordes a las nuevas realidades del Ecuador.

\section{Fórmula estratégica empresarial 4Re: reconversión, reinvención, resiliencia y resguardo}

Las pymes en Ecuador enfrentan un conjunto de problemas que deben atender tanto la oferta como la demanda, ante las altas tasas de contagios. Desde la oferta, estas empresas experimentan limitaciones de movimiento de los trabajadores y acceso a materia prima o insumos, falta de continuidad en la cadena de suministro, ello aunado a que históricamente han tenido debilidades en cuanto a "falta de información, asistencia técnica, capacitación, acceso a crédito y modernización, entre algunos de los factores que han influenciado para que las Mipymes no hayan podido expandir sus productos en el mercado internacional" (Onofa, 2013, p. 151). Asimismo, el Centro de Comercio Internacional (2020) señala que:

[...] tienden a depender de una base de suministro más limitada y son menos capaces de cambiar de proveedor rápidamente si la respuesta covID-19 les impide. Acceso a insumos esenciales. También tienden a tener menos activos y menos efectivo que las más grandes empresas y les resulta más difícil acceder a créditos, lo que significa que repentina y prolongada las caídas en los ingresos. (p. 1)

Y desde la demanda, la poca confianza ha disminuido el acceso a nuevos clientes, así que la complejidad del entorno ecuatoriano les exige a las pymes motorizar capacidades de respuestas y para ello deben activar sus bondades: flexibilidad y adaptación ipso facto, para atender con carácter de urgencia las necesidades de los consumidores y reacomodarse 
en su segmento de mercado para no ceder espacio a la competencia y evitar pérdida de clientes y, por tanto, de ingresos.

En tal sentido, las estrategias empresariales cobran un rol preponderante, porque las empresas requieren, según Camacho, un "enfoque gerencial que permit[a] a la alta dirección determinar un rumbo claro, y promover las actividades necesarias para que toda la organización trabaje en la misma dirección" (2002, p. 2). Esto conlleva superar la tradicional gestión e involucrar desde sus intereses financieros hasta el manejo de sus recursos organizacionales, lo cual implica elegir y desarrollar acciones "tomar unos caminos y descartar otros, con el fin de modificar el equilibrio competitivo y volver a estabilizar la empresa" (Maldonado, 2018, p. 44). Sin embargo, para Ronda y Macarné (2004), Fernández (2001), Vidal Arizabaleta (2004), Fuentelsaz Lamata et al. (2003) y Victore (2005), dichas estrategias empresariales están orientadas hacia la generación de beneficio económico, creación de valor, ventajas competitivas, crecimiento y desarrollo, entre otras. De ahí que desde estas concepciones se puede aseverar que las estrategias empresariales son acciones que se implementan organizacionalmente en procura de generar valor, beneficios socioeconómicos y capacidades distintivas para competir y crear ventajas competitivas en el mercado.

Basado en lo expuesto, de acuerdo con las características de las pymes y con el entorno que estas afrontan se han diseñado cuatro estrategias empresariales, que conjuntas hacen una fórmula estratégica, denominada: 4Re, idónea en momentos de la covid-19, a saber: 1) reinvención organizacional desde los Objetivos de Desarrollo Sostenible, 2) reconversión del marketing tradicional al marketing digital, 3) resiliencia organizacional y 4) resguardo de la salud, respectivamente.

\subsection{Reinvención organizacional desde los Objetivos de Desarrollo Sostenible}

La Asamblea General de las Naciones Unidas, en el 2015, aprobó una agenda política que denominó Agenda 2030 para el Desarrollo Sostenible, en la cual se desarrollan diecisiete Objetivos de Desarrollo Sostenible (oDs), así como sus metas y fines; al tiempo que promueve la colaboración entre los gobiernos, la sociedad civil y el sector privado 
para un desarrollo sostenible y eficiente de los recursos del planeta. ${ }^{4}$ De acuerdo con las Naciones Unidas (2020), esta agenda es una oportunidad de crecimiento para las pymes, comprensión que inicia con integrar los oDs en la estrategia y las metas en las funciones de las empresas, y desde allí generar el compromiso gerencial con el desarrollo sostenible, promoviendo las prioridades compartidas, lo cual se hará explícito en la formulación de sus planes o proyectos, para que pueda ser ejecutado, evidenciándose en beneficios económicos, sociales y medioambientales, respectivamente. Es pertinente aclarar que no todos los ods serán igualmente relevantes para las pymes y que estas no tendrán la misma capacidad de influencia sobre ellos, por lo que la empresa debe evaluar su impacto para definir las áreas de actuación prioritarias.

Desde esta perspectiva, a la gerencia de las pymes le corresponde identificar aquellos procesos, tecnologías o productos con los cuales generan aportes a los oDs, así como las actividades que requieren mejoras, medir los impactos a lo largo de la cadena de valor, concentrar sus esfuerzos por crear vínculos para movilizar los esfuerzos locales, regionales, nacionales y globales en torno a un conjunto de metas comunes. De allí que "los oDs reconocen explícitamente el rol fundamental que las empresas pueden y deben desempeñar en su logro" (Remacha, 2017, p. 6).

Así, pues, las pymes también están llamadas a insertarse en estos objetivos, como entes que integran la sociedad, y también tienen el deber de contribuir a alcanzar los ons y a minimizar los obstáculos al crecimiento en sociedades más justas, procurando espacios para el desarrollo de actividad en mercados estables, con sistemas transparentes, energía accesible y personas económicamente activas especializadas dispuestas a laborar. Entre las formas de participación se encuentran las alianzas entre los ámbitos público-privados en el desarrollo de actividades, así como su inserción en cadenas de valor, lo cual implica acceso a financiación y apoyo en la movilización de recursos. Ambas estrategias dan cabida a la conformación de nuevos segmentos y a la explotación de nichos de mercados, entre otros, con lo cual se pueden ofrecer avances en atender algunas metas de los oDs.

4 Una vez publicada por las Naciones Unidas la Agenda 2030, organizaciones como Global Reporting Initiative y el Consejo Empresarial Mundial para el Desarrollo Sostenible publicaron una guía titulada en castellano: La brújula de los ODS, la cual explica la inserción de estos al sector empresarial y la forma de incorporar la sostenibilidad a la estrategia del negocio. 
Otro motivo por el cual las pymes en Ecuador pueden reinventarse desde el plano organizacional, a partir de los oDs, es porque tienen demarcados sus objetivos y metas, los cuales orientan las estrategias en las actividades económicas, así como las debilidades y riesgos, y desde allí realizan la planificación, así como la construcción de indicadores de monitoreo y evaluación sobre la gestión empresarial y su integración con los oDs, en pro de la creación de valor socioeconómico para los dueños de esas empresas.

En ese mismo devenir, la integración es un factor clave, pues se van acentuando y consolidando las relaciones con entes del Gobierno, organizaciones no gubernamentales, multinacionales, empresas de otros sectores económicos, entidades sociales, entre otros. Ello asegura que el negocio se inserte en las expectativas de sus grupos de interés, además que se abran conversaciones de consultas sobre criterios de responsabilidad, identificación de requerimientos e inquietudes para la toma de decisiones, pero sobre todo que se interrelacionen adecuadamente para obtener confianza y mantener la legitimidad gerencial. Y en la gerencia, desde la sostenibilidad, por supuesto, que prime la eficiente gestión de recursos, pues ello implica menos costos, así como el manejo de datos y seguimiento estadístico que permiten medir la productividad, la confianza, los resultados, la satisfacción de los clientes/consumidores, entre otros aspectos. De igual forma, esta gerencia maneja los retos del contexto en pandemia que afectan a todos los involucrados, coadyuvando a alcanzar tanto los objetivos propios y los compartidos; visibilizando el compromiso social, las iniciativas, la reputación y el reconocimiento ante sus clientes y la sociedad en general; insertándose en redes de conocimiento; actualizando capacidades y tecnologías; así como haciendo una reconversión del marketing tradicional al marketing digital, estrategia que se presenta a continuación.

\subsection{Reconversión del marketing tradicional al marketing digital}

Desde que el Gobierno nacional invocó al aislamiento social o confinamiento, fue un llamado implícito de atención a la gerencia de las pymes en Ecuador, que las haría percatarse de que la manera tradicional de mercadear sus productos/servicios no correspondía al nuevo escenario comercial que se estaba gestando. Ello ha demostrado que deben hacer un salto al ecosistema digital, ${ }^{5}$ el cual, de acuerdo con Katz (2015) es "un nuevo contexto

"El ecosistema digital, entendido como el conjunto de prestaciones y requerimientos de diversa naturaleza que se proveen desde y a través de las redes de telecomunicaciones, el conjunto de infraestructuras y prestaciones asociadas que habilitan la 
industrial y de impacto económico y social resultante de la adopción masiva de tecnologías digitales de información y comunicación y el internet" (p. 5), mediante la digitalización de contenidos y procesos productivos, plataformas de transporte, aplicaciones de provisión de servicios de comunicación (WhatsApp, Telegram), plataformas de búsqueda (Google, Bing), plataformas de comunicación (Zoom), redes sociales (Facebook, Instagram, Pinterest, TikTok, Taringa!) y los dispositivos multifuncionales que han acabado las distancias físicas entre empresa-cliente/usuarios en tiempo real y han introducido cambios en los procesos organizacionales "tendientes a aumentar la productividad, facilitar la interrelación entre sectores industriales, y rediseñar las fronteras de eficiencia de las firmas" (Banco de Desarrollo de América Latina, 2017, p. 116).

En este marco socioeconómico se ha demostrado la pertinencia y urgencia por implementar la publicidad digital, pues entre sus bondades destaca ser una alternativa eficiente para aumentar la tasa de cobertura del mensaje, optimizar la segmentación y llegar a los consumidores con mayor disposición de pago, en relación con otros canales de comunicación como radio, televisión y prensa escrita. Incluso puede aseverarse que el no invertir en ello conllevará la pérdida competitiva y hasta la salida del segmento de mercado.

El uso de tecnología, innovación y mejoramiento de la calidad son elementos que contribuyen a mejorar la competitividad local e internacional de estas empresas; sin embargo, en el "Ecuador solo el 30\% de las pymes utiliza las ventajas tecnológicas de información y comunicación (TIC)" (Onofa, 2017, p. 154). Esta posición sobre las TIC debe cambiar si las pymes que se encuentran activas quieren mantenerse y seguir compitiendo; es necesario considerarlas entre las decisiones de inversión, así como concebir los negocios desde la tecnología. Esto implica actualizar las competencias gerenciales y contratar a profesionales (freelancer) para el desarrollo del marketing digital en aspectos básicos como diseño de página web, manejo de cuentas digitales, publicidad línea, comercio electrónico, manejo de redes sociales, uso de plataformas digitales, entre otros.

prestación de dichos servicios, así como la interacción entre los prestadores de servicios de distinta naturaleza que constituyen la cadena de valor extendida de servicios de Internet, constituye un nuevo sujeto de análisis desde el que se debe pensar las políticas públicas" (Katz, 2015, p. xvII). 
Concebir los negocios desde la tecnología involucra la conformación de alianzas para constituir plataformas gratuitas para el desarrollo de la comercialización en línea. Al respecto se tienen interesantes experiencias en actividades económicas tradicionales, a saber:

[...] más de 10.000 emprendedores y pymes se agrupan en plataformas digitales ${ }^{6}$ en Ecuador e iniciativas creadas durante la pandemia CoviD-19 para salvar sus negocios. Desde una red de panadería, ferreterías y hasta de tiendas se encuentran en estos espacios digitales. Unos venden a través de WhatsApp, Facebook, Instagram y otros en sus propios sitios web. (Zapata Mora, 2020, p. 1)

Y desde esa apertura con una empresa de producción artesanal se comparte la experiencia del propietario de la panadería Pan Nuestro (Quito), quien comenta que:

Este portal fue desarrollado el pasado 11 de mayo con el apoyo de la empresa Moderna Alimentos. Y en esta pandemia se estrenó con las entregas a domicilio. He llegado a clientes que no podía, yo uso la plataforma todo el día y tengo pedidos hasta en la noche. Como panadero pienso que las herramientas modernas me han ayudado a que mi producto artesanal llegue a otros lados. (Zapata Mora, 2020, p. 1)

Desde la misma dinámica, pero en otra actividad económica, como es el sector ferretero, De Stefano indica que:

Ferrimax es una asociación de ferreteros independientes del Ecuador, que creó el sitio ferrimaxcerca.ec el pasado 24 de abril. Tiene registrada 1700 ferreterías y 300 profesionales como ingenieros, arquitectos, gasfiteros que ofrecen sus servicios y esta iniciativa apunta a la solución de problemas como el acceso a información gratuita. Por causa del CoviD-19 las ferreterías y los profesionales afines están pasando por una situación muy difícil. La mayoría de ellas necesitan seguir trabajando ahora y no tienen portales de pedidos en línea como las grandes cadenas. Decidimos actuar con

6 "Existen dos tipos de plataformas: las plataformas en línea, en las cuales el trabajo se terceriza mediante convocatorias abiertas a una audiencia geográficamente dispersa (una modalidad también conocida como crowdwork), y las aplicaciones (apps) móviles con geolocalización, en las que el trabajo se asigna a individuos situados en zonas geográficas específicas" (Organización Internacional del Trabajo, 2019, p. xv). 
una solución que facilite la relación entre compradores y ferreteros. (citado en Zapata Mora, 2020, p. 1)

Estas experiencias demuestran que, a pesar de las adversidades históricas que ha vivido la sociedad empresarial en Ecuador, ha sido la época de la covid-19 cuando las pymes han comenzado a insertarse en el ecosistema digital; sin embargo, solo es el primer paso y aunque parezca un paso grande no es suficiente, pues las bondades tecnológicas abren una pluralidad de opciones tanto individuales como colectivas, donde las colaboraciones entre empresas de diferentes actividades se unen para atender un mismo mercado meta o similares, y en muy corto plazo pueden llegar a un mayor número de potenciales clientes de una manera más rápida. Por ejemplo: colaboración entre empresas y fundaciones, entre una farmacia (compras en línea) y servicios profesionales médicos en línea, así como compras en línea en supermercados y servicio de domicilios por parte ciclistas, entre otros.

Por otra parte, también es importante considerar que las alianzas estratégicas facilitan la diversificación de productos/servicios para ampliar las alternativas al consumidor; por ejemplo, una marca de alimentos orgánicos con su tienda en línea puede aliarse con un licenciado en nutrición y ambos ofrecer sus productos y servicios y así tener cuentas con diversificación de ofertas, a diferencia del trabajo individual. Son tantas las bondades que ofrecen las TIC y conjuntamente con el marketing que las pymes deben dar un salto al ecosistema digital. Para obtener mejores resultados es necesario la convergencia con la resiliencia organizacional, pues es estratégicamente propicio, y su explicación corresponde al siguiente apartado.

\subsection{Resiliencia organizacional}

Definitivamente, la covid-19 ha sido una circunstancia inesperada, que ha ocasionado cambios abruptos en la sociedad ecuatoriana, pues sorprendió la cotidianidad y limitó la operatividad y la gestión empresarial. Esta es una de las circunstancias que las empresas han debido enfrentar, pues han habido interrupciones en las cadenas de suministro, parálisis de los mercados internos, incluso del transporte público, por lo que se ha tenido que optar por la informalidad, obviando cualquier planificación, para poder afrontar la incertidumbre temporalmente y continuar gestionando las empresas; pero regresar al 
ritmo y dinámica económica exige la implementacion de esta estrategia organizacional pertinente en esta época.

Las pymes, como entes sistémicos que integran un macrosistema (economía, comunidad y asociaciones), necesitan lidiar con la incertidumbre del mercado, perturbaciones en la cadena de valor, cambios en las preferencias de los consumidores, nuevos direccionamientos legales y otras sorpresas que puedan ir surgiendo diariamente, que agobian la continuidad del negocio y a las empresas como un todo, porque afectan el funcionamiento general e implican riesgos latentes. Ante estas circunstancias, la resiliencia ${ }^{7}$ organizacional $^{7}$ resulta idónea, porque — de acuerdo con Mitchell y Harris (2012) — fusiona ideas de diversas disciplinas en procura de medir y cualificar su estabilidad en el macrosistema, así como en su sistema, y en aspectos que inciden directamente como la psicología organizacional, las ciencias del comportamiento y el riesgo económico, que buscan, según Wildavsky (1988), proveerse de multicapacidades dinámicas de adaptabilidad y sostenibilidad de la organización con el tiempo.

En este marco socioeconómico, las pymes en el país tienen la labor de interiorizarse como sistemas resilientes, para que puedan subsistir inter e intrageneracionalmente, procurando el equilibrio ante las presiones de la producción con las presiones crónicas de protección. De ahí que tengan una capacidad reactiva de respuesta casi inmediata, que implique reconsiderar desde las bases del negocio hasta la pertinencia de sus productos, para que pueda tomar ventaja de las empresas rivales, anticiparse a las amenazas del entorno y explotar las oportunidades del mercado. Para ello la gerencia se deberá desligar de comodidades, es decir, deslindarse de la gestión tradicional y asumir retos, aunque implique un cambio de paradigma y un:

[...] el desafío cognitivo de eliminar la negación, la nostalgia y la arrogancia; el desafío estratégico de aprender a crear abundantes experimentos tácticos pequeños; el desafío político de reubicar los recursos financieros y humanos donde éstos produzcan mayores retornos; y el desafío ideológico de entender que la renovación estratégica es tan importante como la optimización. (Välikangas \& Hamel, 2003, p. 1)

"rasgo que tienen algunos sistemas y que les permite responder a necesidades repentinas y no anticipadas para la actuación y después volver a su condición normal de funcionamiento con rapidez y con una mínima merma de su rendimiento" (Cook \& Nemeth, 2013, p. 321). 
Por eso la resiliencia organizacional también tiene un matiz de aprendizaje empírico y pragmático desde la teoría del aprendizaje organizacional (Senge, 2006), como fuente para actualizar habilidades, adquirir nuevas capacidades, así como renovar y crear sus ventajas competitivas y sostenibles. Esto para Kuchinke (1995) es un "mecanismo fundamental por el cual las organizaciones, como sistemas abiertos, interactúan con su entorno, procesan información, y se adaptan a las cambiantes condiciones externas e internas” (p. 308), sin perder control de sus actividades, sino que es capaz de continuar y hasta cambiar con autenticidad. De ahí que se pueda afirmar que concebir la resiliencia organizacional como una estrategia empresarial de las pymes es una autoregeneración ipso facto para superar los riesgos a la quiebra y salida del mercado local y nacional, la cual requiere contar con personas que resguarden su salud, mediante la higiene personal y procurar seguridad empresarial, aspecto que se desarrolla en el siguiente aparatado.

\subsection{Resguardar la salud}

En todo tipo de organización, la prioridad gerencial con todos sus integrantes es resguardar la salud y la seguridad de todas las personas que participan en los procesos organizacionales y, para ello, se debe gestionar un proceso de capacitación en higiene y seguridad intra y extraempresarial, siguiendo los lineamientos de la Organización Internacional del Trabajo y de la Organización Mundial de la Salud, pues la educación sobre protocolos de detección, contención y contaminación del virus, a veces, se da por sobreentendida en el personal interno, pero grandes son las sorpresas que se experimentan entre compañeros de trabajo, así como con proveedores, clientes y personas externas. Por ello, resulta importante que en las pymes se acaten las normas de salud ocupacional, se enseñen a todas las personas involucradas los síntomas de la covid-19 y su diferencia con resfriados, así como las maneras de prevenir el contagio individual y masivo y las formas de cuidados ante contagios (directos o de familiares) para que las personas se sientan seguras en sus espacios de trabajos y ello no sea un factor de distracción o de preocupación en la jornada laboral.

También es importante actualizar las políticas para el trabajo a distancia, considerando los mecanismos de trabajos remotos y flexibles; garantizar la disponibilidad de insumos como tapabocas, guantes, alcohol, gel antibacterial, termómetros digitales, trajes de bioseguridad; mantener informada a las personas sobre los niveles de contagio en la región; 
minimizar las reuniones físicas, y cuando sean necesarias procurar mantener distancia prudencial entre los participantes; preparar planes de emergencia ante cualquier contagio y sustitución de puestos de trabajo; entre otros.

Un cambio importante sobre este tema se refiere a la elaboración de planes de limpieza y desinfección profunda de instalaciones y superficies. Ya no puede ser algo esporádico, sino permanente y con productos adecuados, conjuntamente con una ventilación apropiada del área de trabajo, aunque implique reacondicionamiento de espacios para facilitar el distanciamiento entre personas y coadyuvar a gestionar la carga emocional, así como buscar canales de comunicación alternos o aplicaciones en línea con sus contratistas, proveedores, clientes y demás personas que tengan vínculos directos con las empresas, en procura de disminuir el contacto físico al máximo.

La higiene y la seguridad empresariales implica una corresponsabilidad de ambas partes, si ya se mencionaron las más inmediatas por parte del dueño o gerente, también es necesario destacar que los empleados tienen la responsabilidad de cumplir con los protocolos de bioseguridad, utilizando los dispositivos de seguridad y los equipos de protección correctamente durante el tiempo de permanencia en el lugar de trabajo, pues con ello se vela por la seguridad de sus compañeros de trabajo, conjuntamente con información que explique los riesgos para la salud en su trabajo el no cumplir con las medidas de seguridad.

En el ámbito internacional se han impulsado protocolos de bioseguridad ante la pandemia. Al respecto se aconseja impulsar el teletrabajo, flexibilizar las jornadas laborales, agrupar a los empleados por turnos y horarios para minimizar la exposición física frente al virus, reportar casos sospechosos a instancias de salud públicas, buscar apoyo en materia de identificación y valoración del riesgo sobre la prevención de la enfermedad, promover entre todos los involucrados con las pymes el uso inteligencia artificial desde herramientas digitales (de aplicaciones de salud, por ejemplo, CoronApp), para registrar su estado de salud, entre otros (González Alarcón \& Pombo, 2020).

Las estrategias empresariales desarrolladas corresponden a una adaptación dinámica e inmediata de las pymes basada en reconversión, reinversión, resiliencia y resguardo, que inciden en objetivos, estructuras y cultura organizacional, y por tanto en las personas que participan en la empresa, pero sin duda que la clave está en la armonización integrada de las 4Re, 
porque entre ellas existen interdependencias para lograr el equilibrio del sistema empresarial, teniendo en cuenta el entorno y ajustando el direccionamiento estratégico a las necesidades de los consumidores, lo cual no solo colocará a las pymes a la vanguardia competitiva, sino que también exigirá a la gerencia a ampliar sus capacidades y con ello adquirir competencias distintivas que impulsen las ventajas competitivas ante sus competidores.

\section{Conclusión}

Una vez presentado el panorama del Ecuador en pandemia, se consideró importante ofrecer a las pymes un conjunto de estrategias para coadyuvarlas a superar la crisis económica de la nación. En tal sentido, se han presentado cuatro estrategias, que se han denominado 4Re, a saber: a) reinvención organizacional, desde los oDs; b) reconversión del marketing tradicional al marketing digital; c) resiliencia, y d) resguardar la salud, mediante la higiene y seguridad, respectivamente, las cuales están interrelacionadas entre ellas y con todas las actividades, recursos, habilidades, áreas organizativas, y llevan a la creación de valor y ayudan al equilibrio organizacional con competencias distintivas para lograr ventajas competitivas.

Los datos compartidos en este trabajo evidencian que la crisis de salud pública en la sociedad ecuatoriana desafió el sistema socioeconómico inmediato para la nación. Ante esto, se considera que las pymes cumplen un papel protagónico para ayudar a la economía y desde las orientaciones de los ons se hacen aportes más concretos al planeta también, aunque formen parte de los retos sistémicos que debe superar toda la sociedad ecuatoriana.

Sean los oDs una manera para reflexionar sobre la misión corporativa y para reinventar el modelo de negocio desde un nuevo marco para la planificación, el desarrollo y la comunicación, que entrelaza una relación de alianzas entre actores e impulsa el comportamiento responsable de las pymes desde la ética empresarial que procura el bienestar de la sociedad ecuatoriana. 
El desenvolvimiento desde la atmósfera de la pandemia ha sido un aprendizaje para América Latina, en especial para Ecuador, y aun cuando ha habido consecuencias sociales fatales, también es cierto que ha abierto oportunidades para promover el emprendimiento y desplegar una avalancha de diversificación tecnológica que da cuenta de la importancia de las tecnologías digitales para contrarrestar el aislamiento y facilitar el funcionamiento de los sistemas económicos.

El surgimiento de nuevas pymes en el país, basadas en competencias o saberes de vanguardia, demanda en el mercado laboral una de manera contratar de forma independiente (freelancer) a desarrolladores de aplicaciones digitales (una función inexistente en la cadena productiva tradicional) para crear nuevas propuestas de valor, como vinculación entre oferta y demanda para productos específicos (compra-venta de tiquetes de avión, encuentro de oportunidades laborales, entre otras). En ese sentido, la demanda de formación técnica debería estar en aumento inmediatamente.

Las empresas que insertan la resiliencia en la organización en épocas de crisis, cuando existen cambios económicos y sociales, presentan un mejor desempeño desde circunstancias imprevistas o adversas. Para ello, la gerencia y todas las personas que laboran en la empresa deben tener espíritu resiliente, esto es, la capacidad para reinventar, reconvertir su forma de llevar el negocio, resguardar su salud y resistir a los retos que desestabilicen sus gestiones, autorregenerando tanto las empresas como los equipos de trabajo.

Con la implantación de estas estrategias, se intenta pasar del análisis y la decisión a la acción, a la puesta en práctica de la estrategia, a una interacción y reacción inmediata de las pymes, rompiendo con la comodidad tradicional de gestionar las empresas y atreviéndose a insertarse en nuevos espacios que implicarán más que retos, grandes aprendizajes y otra visión del negocio y de gerenciar; pero, sin duda alguna, también conllevarán otro nivel de competencia y desenvolvimiento en el mercado nacional e internacional, para que futuras investigaciones en el corto plazo se aboquen a estudiar el direccionamiento empresarial de las pymes en una economía en crisis e inestabilidad social. 


\section{Referencias}

Alfonzo, I. (1994). Técnicas de investigación bibliográfica. Contexto Ediciones.

Asamblea Nacional de la República del Ecuador. (2020, 22 de junio). Ley orgánica de la de apoyo humanitario para combatir la crisis sanitaria derivada del COVID-19. Oficio AN-SG2020-0355-O. Registro Oficial n. ${ }^{\circ}$ 229. Suplemento. Quito, República del Ecuador.

Asamblea Nacional de la República del Ecuador. (2011, 28 de abril). Ley Orgánica de la Economía Popular y Solidaria y del Sector Financiero Populary Solidario. Oficio T.4887sNJ-11-664. Quito, República del Ecuador.

Banco Central de Ecuador. (2020). El COVID-19 pasa factura a la economía ecuatoriana: Decrecerá entre $7.3 \%$ y $9.6 \%$ en 2020. https://www.bce.fin.ec/index.php/boletines-de-prensa-archivo/item/1366-el-covid-19-pasa-factura-a-la-economia-ecuatorianadecrecera-entre-73-y-96-en-2020

Banco de Desarrollo de América Latina. (2017). Hacia la transformación digital de América Latina y el Caribe: El observatorio CAF del ecosistema digital. Corporación Andina de Fomento. https://scioteca.caf.com/bitstream/handle/123456789/1059/Observatorio\%20 CAF\%20del\%20ecosistema\%20digital.pdf?sequence=7\&isAllowed=y

Camacho, M. (2002). Direccionamiento estratégico: Análisis de una herramienta poderosa. Vía Salud 21(2), 125-137.

Centro de Comercio Internacional. (2020). Apoyar a las pequeñas empresas durante la crisis del CovID-19. http://www.intracen.org/covid19/es/

Cook, R., \& Nemeth, C. (2013). Tomando las cosas con calma: Rasgos cognitivos de dos actuaciones con resiliencia. En E. Hollnagel, D. Woods, \& N. Levenson (Eds.), Ingeniería de la resiliencia: Conceptos y preceptos Valencia (pp. 231-249). Modus Laborandi.

Comisión Económica para América Latina y el Caribe. (2020, 21 de abril). Informe especial dimensionar los efectos del COVI-19 para pensar en la reactivación. https://repositorio. cepal.org/bitstream/handle/11362/45445/4/S2000286_es.pdf

Correa, F., Leiva, V., \& Stumpo G. (2019). Mipymes y heterogeneidad estructural en América Latina. En M. Dini y G. Stumpo (Coords.), Mipymes en América Latina: Un frágil desempeño y nuevos desafios para las políticas de fomento. Síntesis. Documentos de Proyectos (LC/Ts.2019/20). Comisión Económica para América Latina y el Caribe.

Fernández G. (2001). Manual para el desarrollo y crecimiento empresarial. 3R Editores.

Fondo Monetario Internacional. (2020). Declaración de la directora gerente del FMI Kristalina Georgieva tras una conversación ministerial del G-20 sobre la emergencia del coronavirus. Comunicado de prensa n. ${ }^{\circ}$ 20/98. https://www.imf.org/es/News/Articles/2020/03/23/ 
pr2098-imf-managing-director-statement-following-a-g20-ministerial-call-on-the-coronavirus-emergency

Fuentelsaz Lamata, L., Polo Redondo, Y., \& Maicas López, J. P. (2003). Economía digital y estrategia empresarial: Un análisis desde la dirección estratégica. Revista de Empresa, (5), 54-69.

Instituto Nacional de Estadística y Censos (INEC). (2017). Actividades económicas coyuntural. https://www.bce.fin.ec/index.php/component/k2/item/313-indice-de-actividad-econ\%C3\%B3mica-coyuntural-ideac

González Alarcón, N., \& Pombo, C. (2020). ¿Cómo puede la inteligencia artificial ayudar en una pandemia? Banco Interamericano de Desarrollo. http://dx.doi.org/10.18235/0002300

Katz, R. (2015). El ecosistema y la economía digital en américa latina. Ariel.

Kuchinke, K. (1995). Managing learning for performance. Human Resource Development Quarterly, 6(3), 306-316.

Maldonado, J. A. (2018). La estrategia empresarial: Formulación, planeación e implantación. Gestiópolis. https://www.gestiopolis.com/estrategia-empresarial-formulacion-planeacion-e-implantacion/

Mayring, P. (2000). Qualitative content analysis. Forum Qualitative Social Research, 1(2). http://qualitative-research.net/fqs/fqs-e/2-00inhalt-e.htm

Milla, Al. (2020). Coronavirus: ¿Por qué Ecuador tiene el mayor número de contagios y muertos per cápita de covid-19 en Sudamérica? $B B C$. https://www.bbc.com/mundo/noticias-america-latina-52036460

Ministerio de Relaciones Exteriores y Movilidad Humana. (s.f.). Información sobre posición del gobierno de ecuador frente al covid19 sobre las mipymes. http://www.sice.oas.org/ SME_CH/newsletters/documents/Ecuador_COVID_19_MSMES_s.pdf

Mitchell, T., \& Harris, K. (2012). Resilience: A risk management approach. Overseas Development Institute.

Moreno Garcés, L. (2020, marzo). Decreto de Estado de Emergencia Sanitaria. n. ${ }^{\circ} 1017$. Quito, República del Ecuador. https://www.defensa.gob.ec/wp-content/uploads/downloads/2020/03/Decreto_presidencial_No_1017_17-Marzo-2020.pdf

Naciones Unidas. (2020). Pymes y covid-19: Hacia recuperación sostenible. Red Española de Pacto Mundial.

Onofa, M. (2013). Factores asociados a las exportaciones de las pequeñas y medianas empresas-PyMes. En H. Jácome \& K. King, Estudios industriales de la micro, pequeña y mediana empresa. Flacso, Ecuador y Ministerio de Industrias y Productividad del Ecuador. 
Organización de Estados Americanos (oEA). (2020). Políticas de respuesta frente al covid-19. Centro de Información MIPYMEs. http://sice.oas.org/sME_CH/Newsletters/sICE_SME_CH_NL_COvID_19_s.asp

Organización Internacional del Trabajo. (2019). Las plataformas digitales y el futuro del trabajo: Cómo fomentar el trabajo decente en el mundo digital. https://www.ilo.org/wcmsp5/ groups/public/---dgreports/---dcomm/---publ/documents/publication/wcms_684183.pdf

Remacha, M. (2017, abril). Empresa y objetivos de desarrollo sostenible. Cuadernos de la Cátedra Caixa Bank de Responsabilidad Social Corporativa (34). https://media.iese.edu/ upload/st0438.pdf

Ronda, P. G., \& Marcané, J. A. (2004). Dirección estratégica integrada: Un enfoque para integrar los niveles estratégico, táctico y operativo. Instituto de Información Científica y Tecnológica de España.

Senge, P. (2006). The fifth discipline. Doubleday.

Välikangas, L., \& Hamel, G. (2003). En busca de la resiliencia. Harvard Business Review, 81(9), 40-52.

Victore, R. (2005). La dirección integrada de proyectos haciendo uso de las bases de datos en el marco del perfeccionamiento empresarial. Folletos Gerenciales, 9(2), 125-137.

Vidal Arizabaleta, E. (2004). Diagnóstico organizacional: Evaluación sistémica del desempeño empresarial en la era digital. Ecoe.

Wildavsky, A. (1988). Searching for safety. New Brunswick: Transaction Books.

Yance Carvajal, C., Solís Granda, L., Burgos Villamar, I., \& Herminda Hermida, L. (2017, junio). La importancia de las pymes en el Ecuador. Revista Observatorio de la Economía Latinoamericana. http://www.eumed.net/cursecon/ecolat/ec/2017/pymes-ecuador.html

Zapata Mora, B. (2020, 29 de junio). Más de 10000 emprendedores y pymes se agrupan en plataformas digitales en Ecuador; estos son los pasos para registrarse. El Universo. https://www.eluniverso.com/noticias/2020/06/25/nota/7884600/plataformas-digitales-negocios-emprendedores-ecuador

Zevallos, J. (2020). Entrevista con el ministro de Salud de Ecuador, Juan Carlos Zevallos: No se pueden esconder los cadáveres. $B B C$. https://www.bbc.com/mundo/noticias-america-latina-52219012 